\title{
The Role of Weakly Acidic Reflux in Proton Pump Inhibitor Failure, Has Dust Settled?
}

\author{
Emmanouela Tsoukali, MD and Daniel Sifrim, MD, PhD* \\ Barts and The London School of Medicine and Dentistry, Queen Mary, University of London, UK
}

Patients that do not respond satisfactorily to standard proton pump inhibitor (PPI) treatment have become the most common presentation of gastro-esophageal reflux disease (GERD) in third referral gastrointestinal practices. The causes of refractory GERD include lack of compliance with treatment, residual acid reflux and weakly acidic reflux, esophageal hypersensitivity and persistent symptoms not associated with reflux. A role for weakly acidic reflux in symptom generation has been proposed since the availability of impedance-pH monitoring. The possible mechanisms by which persistent weakly acidic reflux might contribute to persistent symptoms in patients under PPI treatment may include esophageal distension by increased reflux volume, persistent impaired mucosal integrity (ie, dilation of intercellular spaces) and/or esophageal hypersensitivity to weakly acidic reflux events. To establish a definite role of weakly acidic reflux in refractory GERD, outcome studies targeting this type of reflux are still lacking. Treatment strategies to reduce the number or effect of weakly acidic reflux could involve drugs that decrease transient lower esophageal sphincter relaxations (ie, baclofen or similar), improve oesophageal mucosa resistance or visceral pain modulators. Finally, anti-reflux surgery can be considered, only if a clear symptom-weakly acidic reflux association was demonstrated.

(J Neurogastroenterol Motil 2010;16:258-264)

Key Words

Proton pump inhibitors, Gastrooesophageal reflux, Heartburn, Regurgitation, Gastric

\section{Introduction}

Gastro-esophageal reflux disease (GERD) is a chronic disorder and remains the most common gastrointestinal-related diagnosis given on office visits. ${ }^{1}$ The introduction of proton pump inhibitors (PPIs) has improved the esophageal mucosal healing and symptom control, however reports on PPI therapeutic failure in GERD patients have increased during the last years. It is estimated that $10 \%-40 \%$ of patients fail to respond symptomatically, either partially or completely, to a standard dose PPI once daily. $^{2-4}$ Of these patients, the majority will continue to have symptoms even with higher doses of PPIs.,

Therapy-resistant patients have become the most common presentation of GERD in third referral gastrointestinal practices. As GERD is the most expensive digestive disease, PPI failure contributes to the increased cost, due to repeated utilization of healthcare resources such as clinic visits, diagnostic tests and prescription medications. ${ }^{7,8}$

Patients with non-erosive reflux disease (NERD) have lower

Received: May 21, 2010 Revised: June 15, 2010 Accepted: June 24, 2010

(c) This is an Open Access article distributed under the terms of the Creative Commons Attribution Non-Commercial License (http://creativecommons. org/licenses/by-nc/3.0) which permits unrestricted non-commercial use, distribution, and reproduction in any medium, provided the original work is properly cited.

*Correspondence: Daniel Sifrim, MD, PhD

Wingate Institute of Neurogastroenterology, 26 Ashfield Street, London E12AJ, United Kingdom

Tel: +44-(0)-207-882-2631, Fax: +44-(0)-207-375-2103, E-mail: d.sifrim@qmul.ac.uk

Financial support: None.

Conflicts of interest: None. 
response rates to acid suppressive therapy than those who have erosive esophagitis. ${ }^{9}$ Pooled symptomatic response rate to PPIs once daily at 4 weeks is only $37 \%$ for patients with NERD versus $56 \%$ for patients with erosive esophagitis. ${ }^{10,11}$ Moreover, symptomatic response to PPIs in patients with NERD is correlated with the extent of esophageal acid exposure. The patients with esophageal acid exposure within the normal range have the lowest response rate to PPIs once daily. ${ }^{12}$

There is no consensus definition of refractory GERD. Most investigators suggest that only patients, who experience partial or lack of response to PPIs twice daily, should be considered as PPI failure. ${ }^{13,14}$ However, there is no GERD-related indication or re-imbursement policies for PPIs twice daily and, therefore, most studies on refractory GERD only include patients that remain symptomatic with PPI once daily.

In many cases it is unlikely that the patients' persistent symptoms are due to gastro-esophageal reflux and a carefully taken history would reveal an alternative diagnosis. ${ }^{15}$ Recent studies performed with esophageal $\mathrm{pH}$-impedance monitoring have shown that up to $63 \%$ of refractory GERD patients report symptoms that cannot be correlated with any type of gastro-esophageal reflux. $^{16,17}$

Various hypotheses have been suggested to explain persistent symptoms in spite of adequate PPI treatment. Of them, esophageal hypersensitivity to persistent reflux (weakly acidic/alkaline or bile reflux) seems to be the most plausible underlying mechanism at least in part of these patients. ${ }^{5,18}$

\section{Definition of Weakly Acidic Reflux}

A recent consensus report provided a detailed nomenclature for reflux patterns detected by impedance $\mathrm{pH}$ monitoring. ${ }^{19}$ An impedance detected reflux is defined as acid when the esophageal $\mathrm{pH}$ falls to $<4$, or when reflux occurs with the esophageal $\mathrm{pH}$ already $<4$. When the esophageal $\mathrm{pH}$ falls by $\geq 1$ unit, but remains $>4$, it is considered "weakly acidic reflux." The term "weakly alkaline reflux" is reserved for reflux episodes during which the esophageal $\mathrm{pH}$ increases to $>7$. An alternative clinical classification prevalent in much of the literature considers acid (nadir $\mathrm{pH}<4$ ), or non acid (nadir $\mathrm{pH}>4$ ) reflux with non acid reflux further separated into weakly acidic (nadir $\mathrm{pH}$ 4-7) or weakly alkaline (nadir $\mathrm{pH} \geq 7$ ). ${ }^{20}$

Although commonly considered as synonym, duodenogastro-esophageal reflux (DGER) and weakly acidic reflux are different type of events. Most DGER occurs in an acidic envi- ronment.

\section{Prevalence of Weakly Acidic Reflux in Refractory GERD}

The prevalence of weakly acidic reflux in refractory GERD depends on the conditions considered to perform reflux monitoring. Although several weakly acidic reflux episodes can be detected during 24-hour impedance-pH monitoring performed "off” PPI, this type of refluxate becomes particularly significant during studies performed "on" PPI. ${ }^{16,17,21,22}$ Vela et $\mathrm{al}^{22}$ used stationary impedance-pH monitoring to compare postprandial recordings of the same subject "on" and "off” PPI. The treatment provoked no reduction in the total number of reflux events, but there was a shift in the refluxate's $\mathrm{pH}$ from acidic to weakly acidic. Heartburn was replaced by regurgitation, which became the predominant symptom in these patients. Studies in patients with refractory GERD showed that weakly acidic reflux could be associated with $30 \%-40 \%$ of symptoms. ${ }^{16,17}$

For example, a study in 168 refractory GERD patients demonstrated that $37 \%$ of patients had a positive association (symptom index [SI]) between symptoms and weakly acidic reflux. Typical GERD symptoms (particularly regurgitation) were more likely to be associated to weakly acidic reflux (42\%), compared with atypical symptoms $(22 \%){ }^{16}$

Zerbib et $\mathrm{al}^{17}$ observed a positive symptom-association between reflux and symptoms in 41 of 74 symptomatic patients (55\%) who were not receiving PPI therapy and in 22 of 60 symptomatic patients (37\%) who were receiving PPI therapy. A temporal relationship was established between symptoms and weakly acidic reflux in $4.1 \%$ and $16.7 \%$ of patients who were "off" and “on” PPI therapy, respectively.

In a recent retrospective review of 200 PPI refractory patients, it was found that $50 \%$ had only persistent weakly acidic reflux and the other 50\% had mixed acid and weakly acidic reflux. More than half of these patients had a negative SI, suggesting functional heartburn rather than GERD. ${ }^{23}$

\section{Potential Mechanisms for Weakly Acidic Reflux-Related Symptoms}

The mechanisms by which weakly acidic reflux can provoke persistence of symptoms in patients "on" PPI remain controversial. It has been proposed: (1) esophageal distension by increased reflux volume, (2) persistent impairment of esophageal 
mucosa due to weakly acidic reflux containing bile acids and (3) esophageal hypersensitivity to non-acid components of gastric contents.

The proximal extent of reflux can be used as an indirect or surrogate measure of reflux volume. It has been demonstrated that proximal extent of reflux is the most important determinant for reflux perception in patients with refractory GERD symptoms. ${ }^{24,25}$ However, studies showed considerable overlap in the proximal extent of symptomatic and asymptomatic weakly acidic reflux events. Thus far, there is no evidence that weakly acidic reflux events have a particularly large volume.

Balloon distension and barostat studies have demonstrated that the proximal esophagus is more sensitive and less compliant than the distal part. ${ }^{26-29}$ Mixed weakly acidic reflux events, containing gas, might produce increased distension of the proximal esophagus. Recent studies confirm that the presence of gas in the refluxate increase the probability that a reflux event will be perceived. $^{18,25,30}$ These findings can explain why mixed - weakly acidic reflux episodes, reaching the proximal esophagus, are more likely to be symptomatic.

Patients with NERD have no macroscopic erosions but mucosal biopsies can show several non specific changes including dilation of intercellular spaces. This finding has been proposed to be very important in the pathophysiology of symptoms in these patients. In human, intraesophageal perfusion with weakly acidic solutions containing bile salts can provoke heartburn. ${ }^{31}$ In vitro studies can explain such finding. Exposure of rabbit esophageal mucosa to weakly acidic solutions containing bile acids (comparable situation to patients "on" PPIs), increases mucosal permeability and induces dilation of intracellular spaces. ${ }^{32}$

Most patients whose symptoms are related to weakly acidic reflux do not have an increased number of reflux events, suggesting esophageal hypersensitivity to less acidic refluxate. ${ }^{33}$ Studies so far have evaluated the relationship between weakly acidic reflux and symptoms in refractory GERD patients. A comparison of this relationship with PPI success patients is warranted ie, a similar degree of weakly acidic reflux in both groups, will reinforce the idea of hypersensitivity to weakly acidic reflux in refractory GERD. ${ }^{14}$

\section{The Role of Weakly Acidic Reflux in Respiratory Disorders}

The role of weakly acidic reflux or aspiration of weakly acidic gastric components in respiratory disorders is still controversial.
Many patients with respiratory disorders are taking PPIs to reduce gastric acid secretion. However, PPI treatment does not prevent patients from aspirating weakly acidic gastric juice. In a recent study, a positive association between cough and weakly acidic reflux has been identified in a subgroup of patients with unexplained chronic cough. ${ }^{34}$ Symptom association analysis was performed using the symptom association probability (SAP). ${ }^{35}$ Overall, 36 of 100 patients showed a positive SAP ( 9 for acid reflux, 23 for weakly acidic reflux and 4 for both acid and weakly acidic reflux). The association between weakly acidic reflux and cough was observed in 15 of 77 patients “off” PPI and 8 of 23 patients “on" PPI. Reflux related-cough might be due to micro-aspiration, vagal reflex originating from the distal esophagus and airway hypersensitivity. ${ }^{36}$

Increased gastro-esophageal reflux is highly prevalent in patients with cystic fibrosis. In these patients, acid reflux is the most common, but weakly acidic reflux may also occur and provoke symptoms in these patients. ${ }^{37}$ Finally, lung transplant patients usually receive PPI treatment. In these patients, aspiration is common, and pepsin and bile acids are frequently found in bronchoalveolar lavage fluid in spite of the PPI therapy. One-half of the lung transplant patients have increased gastro-esophageal reflux, and weakly acidic reflux is particularly common in patients "on" PPI. ${ }^{38}$ Moreover, bile acids in bronchoalveolar lavage fluid was more frequently observed in patients with nocturnal weakly acidic reflux.

\section{The Role of Weakly Acidic Reflux in Mucosal Damage (Erosive Esophagitis and Barrett's Esophagus)}

The number of weakly acidic reflux episodes is not increased in patients with erosive esophagitis compared to patients with NERD and healthy controls. ${ }^{30,39,40}$ These results suggest that weakly acidic reflux does not contribute significantly to esophageal mucosal damage. ${ }^{30,41,21}$

Does weakly acidic reflux have a role in the pathogenesis of Barrett's esophagus? A recent study assessed prevalence of acid and weakly acidic reflux in patients with short-segment Barrett's esophagus. When patients were studied “off” PPI, the number of weakly acidic reflux events was normal. When the study was performed "on" PPI, the majority of persistent reflux was weakly acidic. The authors speculated that pepsin and bile acids in weakly acidic conditions could be relevant for Barrett's transformation. $^{42}$ They suggested that proteolytic activity of pepsin is main- 
tained up to $\mathrm{pH} 5.5$ and denaturation occurs at $\mathrm{pH}>7 .{ }^{43}$ Furthermore, bile acids can impair esophageal mucosal integrity also in a weakly acidic environment. ${ }^{32}$ Therefore, the authors suggested that regression of intestinal metaplasia with long-term PPI therapy would not be expected with persistence of weakly acidic containing bile acids, and in fact it has been reported that regression can occur in only $30 \%$ of short-segment Barrett's esophagus patients. ${ }^{44}$

\section{The Role of DGER in PPI Failure}

It should be emphasized that weakly acidic reflux and DGER are not synonyms. Only $10 \%-15 \%$ of weakly acidic reflux is considered to contain significant amount of bile. A recent study using simultaneous Bilitec and impedance monitoring showed no correlation between the percent time of bilirubin absorbance and weakly acidic reflux parameters. ${ }^{45}$ To the contrary, the majority of bile reflux events occur concomitantly with acid reflux. ${ }^{40,46,47}$

Koek et $\mathrm{al}^{48}$ used combined ambulatory $\mathrm{pH}$ and bilirubin absorbance monitoring to assess patients with GERD who were “off” PPI therapy. In these patients, acid reflux rather than DGER was the main contributor to esophageal symptoms. The positive SAP for acid reflux, DGER and mixed reflux were $22 \%$, $7 \%$ and $10 \%$, respectively.

However, when patients with persistent reflux symptoms despite PPI therapy underwent combined ambulatory $\mathrm{pH}$ and bilirubin absorbance monitoring, there was a higher prevalence of DGER (64\%) than of acid reflux (37\%). ${ }^{21}$ PPI therapy reduces acid and bile reflux, ${ }^{49,50}$ but persistent symptoms could be temporally associated with isolated bile reflux episodes. ${ }^{51}$ Several studies $^{21,31,52}$ provided evidence for a potential contribution of bile acids in the generation of esophageal symptoms. In contrast, a recent study by Gasiorowska et $\mathrm{al}^{53}$ showed that there is no difference in the degree of DGER between patients who failed to respond and those who achieved complete symptom resolution "on" PPI once daily. In this study, persistent symptoms in the PPI failure group were more commonly associated with acid reflux than with DGER.

\section{Treatment of Weakly Acidic Reflux in Patients With Refractory GERD}

Treatment strategies to reduce the number or effect of weakly acidic reflux could involve drugs that decrease transient lower esophageal sphincter relaxations (TLESRs) (ie, baclofen or sim- ilar), improve oesophageal mucosa resistance or visceral pain modulators. Finally, anti-reflux surgery can be considered, only if a clear symptom-weakly acidic reflux association was demonstrated.

\section{Pharmacological Treatment}

All currently used anti-reflux drugs induce a shift in the acidity of the refluxate, whereas they do not decrease the total number of reflux episodes. Most acid and weakly acidic reflux events occur during TLESRs. Baclofen, a gamma-aminobutyric acid B-receptor agonist, was introduced into the clinical arena as a potential add-on treatment for patients who failed PPI treatment (once or twice daily). ${ }^{54,55}$ Baclofen reduces TLESR rate by $40 \%-60 \%$, reflux episodes by $43 \%$, increases lower esophageal sphincter basal pressure, and accelerates gastric emptying. ${ }^{54-56}$ Baclofen has been shown to significantly reduce weakly acidic reflux and DGER, as well as DGER-related symptoms during PPI therapy. ${ }^{57,58}$

Baclofen has central nervous system effects that limit its clinical value for treating GERD. As the drug crosses the bloodbrain barrier, a variety of central nervous system-related side effects may occur including somnolence, confusion, dizziness, lightheadedness, drowsiness, weakness and trembling. Baclofen has short pharmacological half-life (3-4 hours) and necessitates dosing three or more times per day.

Attention is now focussing on the development of new gamma-aminobutyric acid B-receptor agonists that act primarily at peripheral sites and therefore have better tolerability. For example, lesogaberan has a similar pharmacodynamic effect on reflux parameters to baclofen, resulting in almost complete inhibition of TLESRs in $\operatorname{dog}^{59}$ and a similar degree of inhibition as baclofen in healthy subjects and GERD patients. ${ }^{60}$ In contrast to baclofen, however, this agent appears to act in the periphery, with very low incidence of central nervous system-related adverse effects making it more interesting as an add-on therapy for the treatment of GERD patients with incomplete response to PPI therapy.

Until present there are no studies that specifically evaluated the value of visceral pain modulators in patients with refractory GERD. However, given the fact that most of the patients who fail PPI treatment originate from the non-erosive reflux disease group, and that up to $40 \%$ of the PPI failure subjects show a lack of either weak or acidic reflux during intra-esophageal impedance assessment, the usage of these agents is highly attractive. ${ }^{16,61}$ Pain modulators such as tricyclic antidepressants, trazodone and 
selective serotonin reuptake inhibitors have all been shown to improve esophageal pain in patients with non-cardiac chest pain. ${ }^{16,62,63}$ The pain modulators are used in non-mood-altering doses, and they presently provide a therapeutic alternative until more novel and esophageal-specific compounds are available.

So far, controlled pharmacological studies targeting weakly acidic reflux in patients with refractory GERD are unavailable.

\section{Anti-reflux Surgery}

A recent surgical study reported that refractory GERD was a very common (88\%) indication for anti-reflux surgery. ${ }^{64}$ Interestingly, the most common preoperative symptom under failure of medical anti-reflux treatment was regurgitation (54\%). Overall, $82 \%$ of the patients reported that the preoperative reflux symptom completely resolved, and $94 \%$ were satisfied with the results of the surgery. In another study that included only 30 subjects with refractory GERD, who were followed for a period of 12 months, the main preoperative symptoms were regurgitation (93\%) and heartburn (60\%). ${ }^{65}$ At the end of 1 year post surgery, all patients were completely relieved of heartburn, but only $86 \%$ reported resolution of regurgitation. Patient satisfaction rate with the surgery was $87 \%$.

Two recent studies suggest that a positive SI during impedance-pH monitoring in patients "on" PPIs can predict a favorable response to medical or surgical therapy. The first study by Mainie et $\mathrm{al}^{66}$ followed 19 patients who were refractory to a double-dose of PPI and successfully underwent laparoscopic Nissen fundoplication. Prior to surgery, 18 of the 19 patients were found to have a positive SI on esophageal impedance-pH monitoring. After a mean follow-up of 14 months, 16 of the patients with a positive SI were asymptomatic. The second study by Becker et $\mathrm{al}^{67}$ assessed 56 patients with persistent symptoms on a single dose of PPI and abnormal impedance-pH monitoring. Most of these patients had a positive SI and later demonstrated significantly better response to doubling the PPI dose as compared to subjects with normal impedance $\mathrm{pH}$ monitoring. Both of the aforementioned studies were uncontrolled and did not clearly describe whether symptoms were due to weakly acidic reflux or remaining acid reflux, which could have been detected by a simple $\mathrm{pH}$ test and potentially treated with higher-dose PPI. Finally, anti-reflux surgery should be considered, only if a clear symptom-weakly acidic reflux association was demonstrated.

\section{Conclusion}

Management of PPI failure patients remains a challenge. There is a significant overlap of refractory GERD with other disorders, therefore the diagnosis of GERD should always be reconsidered in patients with persistent symptoms despite PPI therapy. In addition, a precise definition of PPI failure and PPI success is needed.

Weakly acidic reflux has been proposed to be one of the underlying mechanisms of refractory GERD. To establish a definite role of weakly acidic reflux in refractory GERD, studies comparing the impact of weakly acidic reflux in patients with PPI failure vs PPI success are lacking and, even more important, we are still waiting for positive controlled outcome studies targeting this type of reflux.

\section{References}

1. Shaheen NJ, Hansen RA, Morgan DR, et al. The burden of gastrointestinal and liver diseases, 2006. Am J Gastroenterol 2006;101: 2128-2138.

2. Fass R. Proton pump inhibitor failure - what are the therapeutic options? Am J Gastroenterol 2009;104(suppl 2):S33-S38.

3. Inadomi JM, McIntyre L, Bernard L, Fendrick AM. Step-down from multiple- to single-dose proton pump inhibitors (PPIs): a prospective study of patients with heartburn or acid regurgitation completely relieved with PPIs. Am J Gastroenterol 2003;98:1940-1944.

4. Carlsson R, Dent J, Watts R, et al. Gastro-oesophageal reflux disease in primary care: an international study of different treatment strategies with omeprazole. International GORD Study Group. Eur J Gastroenterol Hepatol 1998;10:119-124.

5. Martinez SD, Malagon IB, Garewal HS, Cui H, Fass R. Non-erosive reflux disease (NERD) - acid reflux and symptom patterns. Aliment Pharmacol Ther 2003;17:537-545.

6. Bardhan KD. The role of proton pump inhibitors in the treatment of gastro-oesophageal reflux disease. Aliment Pharmacol Ther 1995; 9(suppl 1):15-25.

7. Sandler RS, Everhart JE, Donowitz M, et al. The burden of selected digestive diseases in the United States. Gastroenterology 2002;122: 1500-1511.

8. Gallup. The 2000 Gallup Study of Consumers' Use of Stomach Relief Products. Gallup organization. Princeton 2000

9. Fass R, Fennerty MB, Vakil N. Nonerosive reflux disease - current concepts and dilemmas. Am J Gastroenterol 2001;96:303-314

10. Fass R, Sampliner RE. Barrett's oesophagus: optimal strategies for prevention and treatment. Drugs 2003;63:555-564.

11. Dean BB, Gano AD Jr, Knight K, Ofman JJ, Fass R. Effectiveness of proton pump inhibitors in nonerosive reflux disease. Clin Gastroenterol Hepatol 2004;2:656-664.

12. Fass R, Sampliner RE, Malagon IB, et al. Failure of oesophageal acid control in candidates for Barrett's oesophagus reversal on a very 
high dose of proton pump inhibitor. Aliment Pharmacol Ther 2000;14:597-602.

13. Richter JE. How to manage refractory GERD. Nat Clin Pract Gastroenterol Hepatol 2007;4:658-664.

14. Fass R, Sifrim D. Management of heartburn not responding to proton pump inhibitors. Gut 2009;58:295-309.

15. Bredenoord AJ, Smout AJ. Refractory gastrooesophageal reflux disease. Eur J Gastroenterol Hepatol 2008;20:217-223.

16. Mainie I, Tutuian R, Shay S, et al. Acid and non-acid reflux in patients with persistent symptoms despite acid suppressive therapy: a multicentre study using combined ambulatory impedance-pH monitoring. Gut 2006;55:1398-1402.

17. Zerbib F, Roman S, Ropert A, et al. Esophageal pH-impedance monitoring and symptom analysis in GERD: a study in patients off and on therapy. Am J Gastroenterol 2006;101:1956-1963.

18. Emerenziani S, Sifrim D, Habib FI, et al. Presence of gas in the refluxate enhances reflux perception in non-erosive patients with physiological acid exposure of the oesophagus. Gut 2008;57:443-447.

19. Sifrim D, Castell D, Dent J, Kahrilas PJ. Gastro-oesophageal reflux monitoring: review and consensus report on detection and definitions of acid, non-acid, and gas reflux. Gut 2004;53:1024-1031.

20. Kahrilas PJ, Sifrim D. High-resolution manometry and impedance-pH/manometry: valuable tools in clinical and investigational esophagology. Gastroenterology 2008;135:756-769.

21. Tack J, Koek G, Demedts I, Sifrim D, Janssens J. Gastroesophageal reflux disease poorly responsive to single-dose proton pump inhibitors in patients without Barrett's esophagus: acid reflux, bile reflux, or both? Am J Gastroenterol 2004;99:981-988.

22. Vela MF, Camacho-Lobato L, Srinivasan R, Tutuian R, Katz PO, Castell DO. Simultaneous intraesophageal impedance and $\mathrm{pH}$ measurement of acid and nonacid gastroesophageal reflux: effect of omeprazole. Gastroenterology 2001;120:1599-1606.

23. Sharma N, Agrawal A, Freeman J, Vela MF, Castell D. An analysis of persistent symptoms in acid-suppressed patients undergoing impedance-pH monitoring. Clin Gastroenterol Hepatol 2008;6:521524.

24. Zerbib F, Duriez A, Roman S, Capdepont M, Mion F. Determinants of gastro-oesophageal reflux perception in patients with persistent symptoms despite proton pump inhibitors. Gut 2008;57:156160.

25. Tutuian R, Vela MF, Hill EG, Mainie I, Agrawal A, Castell DO. Characteristics of symptomatic reflux episodes on acid suppressive therapy. Am J Gastroenterol 2008;103:1090-1096.

26. Patel RS, Rao SS. Biomechanical and sensory parameters of the human esophagus at four levels. Am J Physiol 1998;275:G187-G191.

27. Takeda T, Nabae T, Kassab G, Liu J, Mittal RK. Oesophageal wall stretch: the stimulus for distension induced oesophageal sensation. Neurogastroenterol Motil 2004;16:721-728.

28. Drewes AM, Pedersen J, Liu W, Arendt-Nielsen L, Gregersen H. Controlled mechanical distension of the human oesophagus: sensory and biomechanical findings. Scand J Gastroenterol 2003;38:27-35.

29. Karamanolis G, Stevens W, Vos R, Tack J, Clave P, Sifrim D. Oesophageal tone and sensation in the transition zone between proximal striated and distal smooth muscle oesophagus. Neurogastroenterol Motil 2008;20:291-297.

30. Savarino E, Tutuian R, Zentilin P, et al. Characteristics of reflux epi- sodes and symptom association in patients with erosive esophagitis and nonerosive reflux disease: study using combined impedance-pH off therapy. Am J Gastroenterol 2010;105:1053- 1061.

31. Siddiqui A, Rodriguez-Stanley S, Zubaidi S, Miner PB Jr. Esophageal visceral sensitivity to bile salts in patients with functional heartburn and in healthy control subjects. Dig Dis Sci 2005;50: 81-85.

32. Farre R, van Malenstein H, De Vos R, et al. Short exposure of oesophageal mucosa to bile acids, both in acidic and weakly acidic conditions, can impair mucosal integrity and provoke dilated intercellular spaces. Gut 2008;57:1366-1374.

33. Katz P, Gideon RM, Tutuian R. Reflux symptoms on twice daily (BID) proton pump inhibitor (PPI) associated with non acid reflux;a manifestation of hypersensitive esophagus [abstract]. Am J Gastroenterol 2005;128.

34. Blondeau K, Dupont LJ, Mertens V, Tack J, Sifrim D. Improved diagnosis of gastro-oesophageal reflux in patients with unexplained chronic cough. Aliment Pharmacol Ther 2007;25:723-732.

35. Weusten BL, Roelofs JM, Akkermans LM, Van Berge-Henegouwen GP, Smout AJ. The symptom-association probability: an improved method for symptom analysis of 24-hour esophageal $\mathrm{pH}$ data. Gastroenterology 1994;107:1741-1745.

36. Ing AJ, Ngu MC, Breslin AB. Pathogenesis of chronic persistent cough associated with gastroesophageal reflux. Am J Respir Crit Care Med 1994;149:160-167.

37. Blondeau K, Dupont LJ, Mertens V, et al. Gastro-oesophageal reflux and aspiration of gastric contents in adult patients with cystic fibrosis. Gut 2008;57:1049-1055.

38. Blondeau K, Mertens V, Vanaudenaerde BA, et al. Gastro-oesophageal reflux and gastric aspiration in lung transplant patients with or without chronic rejection. Eur Respir J 2008;31:707-713.

39. Conchillo JM, Schwartz MP, Selimah M, Samsom M, Sifrim D, Smout AJ. Acid and non-acid reflux patterns in patients with erosive esophagitis and non-erosive reflux disease (NERD): a study using intraluminal impedance monitoring. Dig Dis Sci 2008;53:15061512.

40. Sifrim D, Holloway R, Silny J, et al. Acid, nonacid, and gas reflux in patients with gastroesophageal reflux disease during ambulatory 24-hour pH-impedance recordings. Gastroenterology 2001;120: 1588-1598.

41. Savarino E, Zentilin P, Tutuian R, et al. The role of nonacid reflux in NERD: lessons learned from impedance-pH monitoring in $150 \mathrm{pa}-$ tients off therapy. Am J Gastroenterol 2008;103:2685-2693.

42. Frazzoni M, Savarino E, Manno M, et al. Reflux patterns in patients with short-segment Barrett's oesophagus: a study using impedance-pH monitoring off and on proton pump inhibitor therapy. Aliment Pharmacol Ther 2009;30:508-515.

43. Roberts NB. Review article: human pepsins - their multiplicity, function and role in reflux disease. Aliment Pharmacol Ther 2006; 24(suppl 2):2-9.

44. Horwhat JD, Baroni D, Maydonovitch C, et al. Normalization of intestinal metaplasia in the esophagus and esophagogastric junction: incidence and clinical data. Am J Gastroenterol 2007;102:497-506.

45. Pace F, Sangaletti O, Pallotta S, Molteni P, Porro GB. Biliary reflux and non-acid reflux are two distinct phenomena: a comparison between 24-hour multichannel intraesophageal impedance and bilir- 
ubin monitoring. Scand J Gastroenterol 2007;42:1031-1039.

46. Sifrim D. Acid, weakly acidic and non-acid gastro-oesophageal reflux: differences, prevalence and clinical relevance. Eur J Gastroenterol Hepatol 2004;16:823-830.

47. Vaezi MF, Lacamera RG, Richter JE. Validation studies of Bilitec 2000: an ambulatory duodenogastric reflux monitoring system. Am J Physiol 1994;267:G1050-G1057.

48. Koek GH, Tack J, Sifrim D, Lerut T, Janssens J. The role of acid and duodenal gastroesophageal reflux in symptomatic GERD. Am J Gastroenterol 2001;96:2033-2040.

49. Champion G, Richter JE, Vaezi MF, Singh S, Alexander R. Duodenogastroesophageal reflux: relationship to $\mathrm{pH}$ and importance in Barrett's esophagus. Gastroenterology 1994;107:747-754.

50. Netzer P, Gut A, Brundler R, Gaia C, Halter F, Inauen W. Influence of pantoprazole on oesophageal motility, and bile and acid reflux in patients with oesophagitis. Aliment Pharmacol Ther 2001;15:1375-1384.

51. Todd JA, Basu KK, de Caestecker JS. Normalization of oesophageal $\mathrm{pH}$ does not guarantee control of duodenogastro-oesophageal reflux in Barrett's oesophagus. Aliment Pharmacol Ther 2005;21:969-975.

52. Vaezi MF, Richter JE. Role of acid and duodenogastroesophageal reflux in gastroesophageal reflux disease. Gastroenterology 1996; 111:1192-1199.

53. Gasiorowska A, Navarro-Rodriguez T, Wendel C, et al. Comparison of the degree of duodenogastroesophageal reflux and acid reflux between patients who failed to respond and those who were successfully treated with a proton pump inhibitor once daily. Am J Gastroenterol 2009; 104:2005-2013.

54. Lidums I, Lehmann A, Checklin H, Dent J, Holloway RH. Control of transient lower esophageal sphincter relaxations and reflux by the GABA(B) agonist baclofen in normal subjects. Gastroenterology 2000;118:7-13.

55. Zhang Q, Lehmann A, Rigda R, Dent J, Holloway RH. Control of transient lower oesophageal sphincter relaxations and reflux by the $\mathrm{GABA}(\mathrm{B})$ agonist baclofen in patients with gastro-oesophageal reflux disease. Gut 2002;50:19-24.

56. Omari TI, Benninga MA, Sansom L, Butler RN, Dent J, Davidson GP. Effect of baclofen on esophagogastric motility and gastroesophageal reflux in children with gastroesophageal reflux disease: a randomized controlled trial. J Pediatr 2006;149:468-474.

57. Vela MF, Tutuian R, Katz PO, Castell DO. Baclofen decreases acid and non-acid post-prandial gastro-oesophageal reflux measured by combined multichannel intraluminal impedance and $\mathrm{pH}$. Aliment Pharmacol Ther 2003;17:243-251.

58. Koek GH, Sifrim D, Lerut T, Janssens J, Tack J. Effect of the GABA(B) agonist baclofen in patients with symptoms and duodeno-gastro-oesophageal reflux refractory to proton pump inhibitors. Gut 2003;52:1397-1402.

59. Branden L, Fredriksson A, Harring E, Jensen J, Lehmann A. The novel, peripherally restricted GABAB receptor agonist lesogaberan (AZD3355) inhibits acid reflux and reduces esophageal acid exposure as measured with 24-h pHmetry in dogs. Eur J Pharmacol 2010;634:138-141.

60. Boeckxstaens GE, Beaumont H, Mertens V, et al. Effects of lesogaberan, a novel GABA(B)-receptor agonist, on reflux and lower esophageal sphincter function in patients with gastroesophageal reflux disease. Gastroenterology Published Online First: 7 May 2010. doi:10.1053/j.gastro.2010.04.051

61. Fass R, Shapiro M, Dekel R, Sewell J. Systematic review: proton-pump inhibitor failure in gastro-oesophageal reflux disease where next? Aliment Pharmacol Ther 2005;22:79-94.

62. Clouse RE, Lustman PJ, Eckert TC, Ferney DM, Griffith LS. Low-dose trazodone for symptomatic patients with esophageal contraction abnormalities. A double-blind, placebo-controlled trial. Gastroenterology 1987;92:1027-1036.

63. Handa M, Mine K, Yamamoto H, et al. Antidepressant treatment of patients with diffuse esophageal spasm: a psychosomatic approach. J Clin Gastroenterol 1999;28:228-232.

64. Rosenthal R, Peterli R, Guenin MO, von Flüe M, Ackermann C. Laparoscopic antireflux surgery: long-term outcomes and quality of life. J Laparoendosc Adv Surg Tech A 2006;16:557-561.

65. Mirbagheri SA, Sadeghi A, Amouie M, et al. Pyloric injection of botulinum toxin for the treatment of refractory GERD accompanied with gastroparesis: a preliminary report. Dig Dis Sci 2008;53: 26212626.

66. Mainie I, Tutuian R, Agrawal A, Adams D, Castell DO. Combined multichannel intraluminal impedance-pH monitoring to select patients with persistent gastro-oesophageal reflux for laparoscopic Nissen fundoplication. Br J Surg 2006;93:1483-1487.

67. Becker V, Bajbouj M, Waller K, Schmid RM, Meining A. Clinical trial: persistent gastro-oesophageal reflux symptoms despite standard therapy with proton pump inhibitors - a follow-up study of intraluminal-impedance guided therapy. Aliment Pharmacol Ther 2007; 26:1355-1360. 